\title{
ANALISIS FAKTOR RISIKO ATONIA UTERI
}

\author{
Melati Julizar ${ }^{1}$, Jusuf S. Effendi' ${ }^{2)}$, Hadyana Sukandar ${ }^{3)}$ \\ ${ }^{1)}$ Program Studi Magister Kebidanan FK Unpad \\ ${ }^{2)}$ Departemen Obstetri dan Ginekologi FKUnpad/RSHS \\ ${ }^{3)}$ Departemen Ilmu Kesehatan Masyarakat FK Unpad \\ E-mail : yulizarmelaty@gmail.com
}

\begin{abstract}
Maternal mortality rate in Indonesia is still relatively high. The biggest cause of maternal mortality in Indonesia is bleeding. Most bleeding in the puerperium (75-80\%) is uterine atony. Uterine atony is the most frequent cause of the occurrence of bleeding postpartum. This study aimed to analyze the risk factors for uterine atony in Cut Meutia General Hospital and Health Center PONED in North Aceh district. This study uses a case control design, as a case group, maternal postpartum hemorrbage with uterine atony and control group, maternal postpartum hemorrbage without uterine atony. The sample size for each selected group 69 (the number of cases during the period from 2015 to 2017) while the control selected at random with the same number as many as 69 cases. Data analysis using chi square and multiple logistic regression. The results of the research bivariable indicates a meaningful associated with uterine atony is preeclampsia with OR 10,30 (CI 95\%: 2,91-36,41), twin pregnancy with OR 17,31 (CI 95\%: 2,21-135,76), induction of labor with an OR 4,39 (CI 95\%: 1,0-21,45), grande multipara with OR 4,52 (CI 95\%: 1,61-12,73) compared with primipara. Multivariable those associated with uterine atony is the age of the mother with OR 2,98 (CI 95\%: 0,5615,82), preeclampsia with OR 20,27 (CI 95\%: 4,66-88,20), induction of labor with an OR 6,69 (CI 95\%: 1,12-39,95), twin pregnancy with OR 52,39 (CI 95\%: 5,65-486,03), anemia with OR 3,06 (CI 95\%: 1,07-8,69). This study concluded that parity, preeclampsia, twin pregnancy and labor induction were risk. factors for the incidence of uterine atony with twin pregnancy as the most dominant factor in the incidence of uterine atony.
\end{abstract}

Keywords : Risk factors; Uterine Atony.

\begin{abstract}
ABSTRAK
Angka Kematian Ibu di Indonesia masih relatif tinggi. Penyebab terbesar kematian Ibu di Indonesia adalah perdarahan. Sebagian besar perdarahan pada masa nifas (75-80\%) adalah akibat atonia uteri. Atonia uteri merupakan penyebab paling sering terjadinya perdarahan postpartum. Penelitian ini bertujuan untuk menganalisis faktor risiko atonia uteri di Rumah Sakit Umum Cut Meutia dan Puskesmas PONED wilayah Kabupaten Aceh Utara. Penelitian ini menggunakan rancangan case control, sebagai kelompok kasus ibu perdarahan postpartum dengan atonia uteri dan kelompok kontrol ibu perdarahan postpartum tanpa atonia uteri. Ukuran sampel untuk masing-masing kelompok dipilih 69 (jumlah kasus selama periode 2015-
\end{abstract}

Cara mengutip: Julizar, Melati ., Effendi, Jusuf S. \& Sukandar, Hadyana. (2019). Analisis Faktor Risiko Atonia Uteri. Care:Jurnal Ilmiah Ilmu Kesehatan, 7(3), 108-117 
2017) sedangkan control dipilih secara random dengan jumlah yang sama sebanyak 69 kasus. Analisis data menggunakan chi kuadrat dan regresi logistic ganda. Hasil penelitian bivariabel menunjukkan yang bermakna berhubungan dengan atonia uteri adalah pre eklamsi dengan OR: 10,30 (IK 95\%: 2,91-36,41), kehamilan kembar dengan OR: 17,31 (IK 95\%: 2,21-135,76), induksi persalinan dengan OR: 4,39 (IK 95\%: 1,0-21,45), paritas $\geq 4$ dengan OR: 4,52 (IK 95\%: 21,61-12,73) bila dibandingkan dengan paritas satu. Secara multivariabel yang berhubungan dengan atonia uteri adalah usia ibu dengan OR: 2,98 (IK 95\%: 0,56-15,82), pre eklamsi dengan OR: 20,27 (IK 95\%: 4,66-88,20), induksi persalinan dengan OR: 6,69 (IK 95\%: 1,12-39,95), kehamilan kembar dengan OR: 52,39 (IK 95\%: 5,65-486,03), anemia dengan OR: 3,06 (IK 95\%: 1,07-8,69). Penelitian ini menyimpulkan bahwa paritas, pre eklamsi, kehamilan kembar dan induksi persalinan merupakan faktor risiko kejadian atonia uteri dengan kehamilan kembar merupakan faktor yang paling dominan terhadap kejadian atonia uteri.

Kata Kunci : Atonia uteri; faktor risiko.

\section{PENDAHULUAN}

Setiap tahun sekitar 830 ibu meninggal akibat komplikasi pada saat kehamilan dan persalinan (Alkema, 2016).Kematian ibu yang paling banyak di dunia diakibatkan perdarahan sebanyak $27,1 \%$ dan lebih dari dua pertiga kematian disebabkan perdarahan postpartum (Say, 2014). Kementerian Kesehatan Republik Indonesia (Kemenkes RI) juga menilai angka kematian ibu masih relatif tinggidi Indonesia. Perdarahan postpartum merupakan penyebab utama kematian ibu Kemenkes (RI, 2018).

Berdasarkan profil kesehatan Aceh, trend kematian ibu masih berfluktuatif, kasus kematian ibu di provinsi Aceh paling tinggi terdapat di Kabupaten Aceh Utara. Pada tahun 2015 Aceh Utara menempati posisi pertama kematian ibu di provinsi Aceh dengan jumlah kematian 15 kasus. Tahun 2016 terjadi peningkatan kematian dengan jumlah 26 kasus, walaupun pada tahun
2017 kematian ibu di Aceh Utara mengalami penurunan yaitu sebanyak 18 kasus dan berada pada urutan ke-2, namun hal ini masih menjadi perhatian khusus (Dinkes Aceh Utara, 2018). Atonia uteri dapat menyebabkan perdarahan, dampak dari perdarahan adalah kematian,terjadinya atonia uteriini disebabkankarena serabut miometrium yang mengelilingi pembuluh darah yang memvaskularisasi daerah implantasi plasenta tidak berkontraksi. Sekitar (75-80\%) perdarahan yang terjadi pada masa nifas diakibatkan atonia uteri (Nurchairina, 2017).

Berdasarkan Gabbe dan Wetta, faktor risiko perdarahan post partum terdiri dari tiga faktor, yaitu faktor ibu, faktor kehamilan dan faktor persalinan. Beberapa penelitian menjelaskan mengenai faktor risiko atonia uteri meliputi overdistensi uterus (kehamilan ganda, polihidramnion, makrosomia janin), induksi persalinan, persalinan lama, usia ibu, paritas, 
preeklamsi, dan kala dua memanjang (Wetta, 2013).

Kabupaten Aceh utara mempunyai satu Rumah Sakit Umum yaitu Rumah Sakit Umum Cut Meutia dan 3 Puskesmas yang mampu PONED (Dinkes Aceh Utara, 2018).vBerdasarkan data rekam medik jumlah persalinan pervaginam di Rumah Sakit Umum Cut Meutia dari tahun 20152017 sebanyak 859 persalinan normal dengan kasus perdarahan post partum sebanyak 167 kasus dan 60 kasus diantaranya adalah atonia uteri. Prevalensi kejadian atonia uteri pada tahun 2015 sebanyak 31\%, tahun $201629 \%$ dan tahun $201735 \%$.

Terlapor kasus kematian ibu karena atonia uteri tahun 2015 sebanyak 1 kasus, 2016 sebanyak 3 kasus dan 20171 kasus (data Rekam Medik, 2018).Sedangkan kejadian atonia uteri di Puskesmas PONED, dari ketiga Puskesmas tersebut dari tahun 20152017 jumlah kejadian perdarahan post partum sebanyak 25 kasus dan 9 kasus adalah atonia uteri (Puskesmas PONED, 2018). Ini menunjukkan bahwa kasus atonia uteri di Rumah Sakit Umum Cut Meutia dan tiga puskesmas PONEDmasih digolongkan tinggi. Tujuan penelitian ini adalah menganalisis faktor risiko atonia uteri dan faktor yang paling utama dan dominan yang berhubungan dengan atonia uteri.

\section{METODE PENELITIAN}

Penelitian ini menggunakan rancangan observasional analitik, dengan desain casecontrol. Rancangan ini dilakukan untuk mencari hubungan antara faktor usia ibu, paritas, preeklamsi, polihidramnion, kehamilan ganda, bayi makrosomia, anemia, induksi persalinan dan kala dua memanjangdengan kejadian atonia uteri.Penelitiandilaksanakan di RSU Cut Meutia dan tiga Puskesmas PONED Kabupaten Aceh Utara. Populasi penelitian semua ibu dengan perdarahan post partum, sampel kasus semua ibu dengan atonia uteri, 69 orang (total kasus) dan kontrol 69 orang (simple randomsampling). Cara pengumpulan data menggunakan data sekunder. Data diolah dan kemudian dianalisis dengan analisis bivariat menggunakan uji Chi Square dan analisis multivariat menggunakan regresi logistik ganda.

\section{HASIL}

Berdasarkan Tabel 1 tampak dari sembilan variabel faktor risiko yang bermakna $(p<0,05)$ ada empat variabel, yaitu paritas, preeklamsi, induksi persalinan dan kehamilan kembar, dari empat faktor risiko yang bermakna berdasarkan nilai odds rasio yang paling tinggi adalah preeklamsi dan kehamilan kembar. Ibu dengan preeklamsi memiliki risiko 10,30 kali untuk terjadi atonia uteri bila di 
bandingkan ibu tanpa preeklamsi. risiko 17,31 kali untuk terjadi atonia uteri Sedangkan kehamilan kembar memiliki dibanding tidak hamil kembar.

Tabel 1. Hubungan faktor risiko dengan kejadian atonia uteri

\begin{tabular}{|c|c|c|c|c|}
\hline \multirow[b]{2}{*}{ Variabel } & \multicolumn{2}{|c|}{ Atonia Uteri } & \multirow[b]{2}{*}{ Nilai $p$} & \multirow[b]{2}{*}{ OR (IK 95\%) } \\
\hline & $\begin{array}{c}\text { Kasus } \\
(\mathrm{n}=69)\end{array}$ & $\begin{array}{l}\text { Kontrol } \\
(\mathrm{n}=69)\end{array}$ & & \\
\hline Usia ibu (tahun) & & & 0,112 & \\
\hline$<20$ & 2 & 8 & & 1.0 \\
\hline $20-35$ & 36 & 29 & & $4,97(0,98-25,21)$ \\
\hline$>35$ & 31 & 32 & & $3,88(0,76-19,70)$ \\
\hline Paritas & & & 0.009 & \\
\hline 1 & 6 & 20 & & 1.0 \\
\hline $2-3$ & 25 & 21 & & $3,97(1,35-11,70)$ \\
\hline$\geq 4$ & 38 & 28 & & $4,52(1,61-12,73)$ \\
\hline Preeklamsi & & & $<0,001$ & \\
\hline $\mathrm{Ya}$ & 22 & 3 & & $10,30(2,91-36,41)$ \\
\hline Tidak & 47 & 66 & & \\
\hline Induksi persalinan & & & 0,049 & \\
\hline $\mathrm{Ya}$ & 8 & 2 & & $4,39(1,0-21,45)$ \\
\hline Tidak & 61 & 67 & & \\
\hline Kala dua memanjang & & & 0,178 & \\
\hline $\mathrm{Ya}$ & 9 & 15 & & $0,54(0,22-1,33)$ \\
\hline Tidak & 60 & 54 & & \\
\hline Anemia & & & 0,072 & \\
\hline $\mathrm{Ya}$ & 21 & 12 & & $2,08(0.93-4,66)$ \\
\hline Tidak & 48 & 57 & & \\
\hline Bayi makrosomia & & & 0,274 & \\
\hline $\mathrm{Ya}$ & 6 & 2 & & \\
\hline Tidak & 63 & 67 & & $3.19(0,62-16,40)$ \\
\hline Kehamilan kembar & & & $<0,001$ & \\
\hline $\mathrm{Ya}$ & 14 & 1 & & $17,31(2,21-135-76)$ \\
\hline Tidak & 55 & 68 & & \\
\hline Polihidramnion & & & 0,245 & \\
\hline $\mathrm{Ya}$ & 3 & 0 & & - \\
\hline Tidak & 66 & 69 & & \\
\hline
\end{tabular}

Tabel 2. Faktor risiko yang berhubungan secara Multivariabel terhadap kejadian atonia uteri berdasarkan regresi logistik ganda (model akhir)

\begin{tabular}{lcccc}
\hline Variabel & Koef B & SE $(\mathrm{B})$ & Nilai p & OR $($ adjIK 95\%) \\
\hline Usia ibu (tahun) & & & 0,016 & $2,98(0,56-15,82)$ \\
20-35 & 1,092 & 0,851 & 0,199 & $0,72(0,12-0-4,35)$ \\
$>35$ & $-0,329$ & 0,918 & 0,721 & $20,27(4,66-4,36)$ \\
Preeklamsi & 3,009 & 0,75 & 0,000 & $6,69(1,12-39,95)$ \\
Induksi persalinan & 1,901 & 0,911 & 0,037 & $52,39(5,65-486,03)$ \\
Kehamilan kembar & 3,959 & 1,137 & 0,000 & $3,06(1,07-8,69)$ \\
Anemia & 1,117 & 0,533 & 0,036 & \\
\hline
\end{tabular}

Dari hasil pemodelan akhir diatas dapat dilihat bahwa faktor yang berhubungan dengan kejadian atonia uteri adalah usia ibu, preeklamsi, induksi persalinan, kehamilan kembar dan anemia. Sedangkan faktor risiko yang paling dominan 
berhubungan dengan kejadian atonia uteri adalah kehamilan kembar.

\section{PEMBAHASAN}

Berdasarkan uji analisis regresi logistik, didapatkan lima faktor yang terdapat hubungan dengan atonia uteri, yaitu variabel usia ibu, preeklamsi, induksi persalinan, kehamilan kembar dan anemia

\section{Preeklamsi}

Temuan penelitian didapatkan hasil bahwa terdapat hubungan preeklamsi dengan atonia uteri dengan nilai $\mathrm{p}=<0,001$ dan $\mathrm{OR}=20,27$. Kesimpulan dari hasil ini adalah ibu dengan preeklamsi kemungkinan berisiko 20,27 kali mengalami atonia uteri dibandingkan ibu yang tidak preeklamsi. Menurut Nugroho tahun 2012 preeklamsi adalah hipertensi pada kehamilan, apabila ditemukan tekanan darah $\geq 140 / 90 \quad \mathrm{mmHg}$ setelah usia kehamilan 20 minggu, disertai dengan proteinuria $\geq 300 \mathrm{mg} / 24$ jam (Achebe, 2016). Pada kondisi berat preeklamsi dapat menjadi eklampsia dengan penambahan gejala kejang-kejang (Manuaba, 2008). Preeklamsi merupakan penyebab kedua kematian ibu di dunia setelah pendarahan (Wiknjosastro, 2008).

Pada penelitian ini ibu dengan preeklamsi dengan atonia uteri sejumlah 22 orang (31,9\%), sehingga dapat dikaitkan bahwa ibu yang pada masa kehamilannya mengalami preeklamsi berisiko mengalami atonia uteri. Pada penelitian lisonkova di Kanada juga memperoleh hasil ada hubungan preeklamsi dengan atonia uteri. Penelitian ini mengamati hubungan yang kuat antara penggunaan magnesium sulfat dengan perdarahan postpartum. Penggunaan magnesium sulfat diindikasikan untuk preeklampsia/eklampsia berat, diketahui bahwa magnesium sulfat memiliki efek tokolitik yang dapat berkontribusi pada atonia uteri (Lisonkova, 2016).

\section{Kehamilan Kembar}

Temuan penelitian ddidapatkan hasil bahwa terdapat hubungan kehamilan kembar dengan atonia uteridengan nilai $\mathrm{p}<0,001$ dan $\mathrm{OR}=52,38$. Kesimpulan hasil ini adalah ibu dengan hamil kembar kemungkinan berisiko 52,38 kali untuk mengalami atonia uteri dibandingkan ibu yang tidak hamil kembar. Menurut Wiknjosastro, menjelaskan bahwa kehamilan kembar dapat didefinisikan sebagai suatu kehamilan dengan terdapat dua/lebih janin sekaligus (Wiknjosastro, 2008). Kehamilan kembar menjadisatu dari banyak faktor yang mengakibatkan terjadinya peregangan pada uterus secara berlebihan. Peregangan uterus yang berlebihan karena hal inidapat membuat uterus tidak mampu berkontraksi segera setelah plasenta lahir sehingga sering menyebabkan terjadinya atonia uteri pada ibu bersalin. Kontraksi uterus merupakan 
cara utama dalam pengontrolan perdarahan setelah melahirkan. Namun apabila cara ini gagal maka dapat mengakibatkan terjadi atoniauteri. Secara fisiologis perdarahan postpartum dikontrol oleh kontraksi serabut miometrium yang mengelilingi pembuluh darah yang memvaskularisasi daerah implantasi plasenta. Namun apabila serabut serabut miometrium tersebut tidak berkontraksi maka akan terjadi atonia uteri. Hasil penelitian dengan analisa bivariat ini menunjukkan jumlah ibu dengan kehamilan kembar 15 orang dan mengalami atonia uteri sebanyak 14 (20,3\%). Hal ini sejalan dengan penelitan Anggrainy yang menyimpulkan bahwa terdapat hubungan overdistensi uterus dengan atonia uteri di RSUD Dr H. Abdul Moeloek Provinsi Lampung (nilai $\mathrm{p}=0,001$, $\mathrm{OR}=4,608)$ (Anggrainy, 2013).

\section{Usia ibu}

Temuan penelitian didapatkan hasil bahwa terdapat hubungan usia ibu dengan kejadian atonia uteri dengan nilai $\mathrm{p}=0,0016$. Pada usia 20-35 tahun dengan nilai $\mathrm{p}=0,199$ dan $\mathrm{OR}=2,98$. Pada usia ibu $>35$ tahun dengan nilai $\mathrm{p}=0,721$ dan $\mathrm{OR}=0.72$. kesimpulan dari hasil ini adalah usia ibu 20-35 tahun kemungkinan berisiko 2,98 kali untuk dapat terjadinya atonia uteri dibandingkan ibu yang berusia $>35$ tahun. Pada usia $<20$ tahun penyulit kehamilan lebih tinggi dibandingkan dengan masa sehatnya usia reproduksi yaitu usia 20-35 tahun. Hal ini disebabkan karena keadaan belum matangnya alat reproduksi untuk hamil pada remaja. Sedangkan usia di atas 35 tahun, organ-organ reproduksinya sudah berkurang kemampuannya dan ke elastisannya dalam menerima kehamilan dan melalui proses persalinan (Lestari, 2014).

Menurut teori manuaba, ibu dengan usia $>35$ tahun mengalami persalinan berisiko terjadinya atonia uteri. Atonia uteri ini terjadi karena kondisi miometrium dan tonus ototnya, sehingga menimbulkan kegagalan kompresi pembuluh darah pada tempat implantasi plasenta yang akibatnya terjadi perdarahan postpartum (Manuaba, 2008). Hasil penelitian dengan analisa bivariat ini menunjukkan paling banyak responden berusia 20-35 tahun dan mengalami ataonia uteri sebanyak 36 $(52,2 \%)$. Hal ini menunjukkan ada kesenjangan antara teori dan hasil penelitian. Berdasarkan faktor risiko hasil penelitian yang dapat membantu dalam kesenjangan penelitian ini adalah sebagian besar ibu mengalami anemia (hb $<11$ gro) $21(30,4 \%)$ dan preeklamsi $22(31,9 \%)$.

\section{Anemia}

Temuan penelitian didapatkan hasil bahwa terdapat hubungan anemia dengan kejadian atonia uteri dengan nilai $\mathrm{p}=0,036$ dan $\mathrm{OR}=3,06$. Kesimpulan dari penelitian ini adalah ibu dengan anemia kemungkinan berisiko 3,06 kali untuk terjadi atonia uteri 
dibandingkan ibu tidak anemia. Menurut Achebe, terjadinya insiden yang tinggi dan komplikasi yang timbul baik pada ibu maupun pada janin disebabkananemia pada kehamilan. Berdasarkan data ibu hamil dengan anemia lebih dari 50\%. Hal ini dapat menyebabkan kesakitan dan kematian ibu hamil (Achebe, 2016). Manuaba juga menjelaskan anemia dapat mempengaruhi daya tahan tubuh ibu dan dapat meningkatkan frekuensi komplikasi kehamilan serta persalinan. Kekurangan kadar hemoglobin dalam darah dapat mengakibatkan oksigen yang dibawa dan di kirim ke sel tubuh maupun sel otak dan uterus berkurang. Kurangnya jumlah oksigen dalam darah mengakibatkan tidak dapat berkontraksinya otot-otot uterus dengan adekuat sehingga dapat menimbulkan terjadi atonia uteri danmengakibatkan perdarahan banyak (Manuaba, 2008).

Pada penelitian ini ibu dengan anemia mengalami atonia uteri sebanyak 21 (30,4\%), sehingga dapat dikaitkan bahwa ibu yang pada masa kehamilannya mengalami anemia berisiko mengalami atonia uteri karena terjadinya gangguan his atau kekuatan mengejan yang dipengaruhi anemia pada persalinan yaitu pada kala tiga diikuti dengan pendarahan postpartum karena atonia uteri dan pada kala empat dapat terjadi perdarahan postpartum sekunder dan atonia uteri (WHO, 2015).

\section{Induksipersalinan}

Temuan penelitian didapatkan hasil bahwa terdapat hubungan induksi persalinan dengan kejadian atonia uteri, nilai $\mathrm{p}=0,037$ dan $\mathrm{OR}=26,69$. Kesimpulan dari hasil ini adalah ibu bersalin yang diinduksi kemungkinan berisiko 6,69 kali untuk terjadinya atonia uteri dibandingkan ibu bersalin yang tidak diinduksi. Menurut cuningham, induksi persalinan merupakan upaya untuk menimbulkan inisiasi persalinan yang selanjutnya menjadi awal dimulainyaproses kelahiran janin dan plasenta (Anwar, 2013). Pematangan serviks atau induksi persalinan dengan farmakologik adalah upaya pematangan serviks menggunakan obat-obatan, antara lain prostaglandin, misoprospol, mifepristone, relaksin dan oksitosin. Dari beberapa obat-obat tersebut yang paling sering digunakan adalah misoprospol dan oksitosin (Tenore, 2003).

Menurut Anggrainy, biasanya obat yang digunakan untuk induksi persalinan menggunakan oksitosin, yaitu suatu hormon yang menyebabkan kontraksi rahim menjadi lebih kuat. Jumlah obat yang diberikan dapat diketahui secara pasti dengan diberikan melalui infus.Kadang terjadi kontraksi yang terlalu kuat, terlalu sering atau terlalu kuat dan terlalu sering. Keadaan ini dikenal dengan kontraksi disfungsional hipertonik dan sulit untuk dikendalikan. Hal ini dapat mengakibatkan 
atonia uteri karena kontraksi uterus yang lemah yang disebabkan penggunaan obatobatan uterotonika yang memaksa uterus berkontraksi (Anggrainy, 2013).

Dalam penelitian ini $11,6 \%$ ibu yang diinduksi saat persalinan mengalami atonia uteri, sehingga dapat dikaitkan bahwa percepatan persalinan olehoksitosin, mengakibatkan atonia uterikarena kesempatan otot untukberetraksi tidak cukup saat uteri telah berkontraksidengan kuat, serta terjadipeningkatan tonus rahim dengan relaksasiyang jelek antara kontraksi. Penelitian ini juga sejalan dengan teori Cunninghambahwa persalinan yang diinduksi maupunyang diperkuat oleh preparat oksitosinlebih besar memungkinkan untuk diikutiperdarahan karena atoniauteri (Cunningham, 2005).

Pada penelitian ini ibu dengan diinduksi pada saat persalinan mengalami atonia uteri sebanyak 21 (30,4\%), sehingga dapat dikaitkan bahwa ibu yang diinduksi pada saat persalinan berisiko mengalami atonia uteri, dengan nilai $\mathrm{OR}=6,69$, sehingga ibu bersalin yang diinduksi kemungkinan berisiko 6,69 kali untuk mengalami atonia uteri dibandingkan ibu yang tidak diinduksi. Hal ini sejalan dengan penelitian yang dilakukan oleh Kristi bahwa terdapat hubungan induksi oksitosin dengan atonia uteri, ibu yang diinduksi oksitosin dan mengalami atonia uteri sebesar 4,213 kali dibandingkan dengan yang tidak diinduksi (Kristi, 2011).

\section{KESIMPULAN}

Berdasarkan hasil penelitian dan pembahasan mengenai Faktor risiko atonia uteri di Rumah Sakit dan Puskesmas PONED wilayah Kabupaten Aceh Utara maka dapat diambil kesimpulan yaitu, faktor yang paling berhubungan dengan atonia uteri adalah kehamilan kembar.

\section{SARAN}

Saran untuk penelitian selanjutnya dilakukan penelitian lanjutan dengan menggunakan pendekatan kualitatif sehingga dapat menggali lebih dalam dan didapatkan informasi yang lebih akurat mengenai faktor yang berhubungan dengan perdarahan postpartum, terutama atonia uteri melalui tenaga kesehatan.

\section{Ucapan Terima Kasih}

Kepada Kepala dinas kesehatan Aceh Utara, Kepala Rumah Sakit Umum Cut Meutia, Kepala Puskesmas Lhoksukon, Kepala Puskesmas Krung Mane, Kepala Puskesmas Nisam, seluruh staff ruang bersalin dan seluruh pihak yang terlibat dan mendukung terlaksananya penelitian ini. 


\section{REFERENSI}

Achebe MM, Gafter-Gvili A. (2016). How I treat anemia in pregnancy: iron, cobalamin and folate. The American Society of Hematology.1-36.

Anggrainy V, Irianto, Irmayanti. (2013). Faktor-Faktor yang Mempengaruhi Kejadian Atonia Uteri. Media Bina Ilmiah. 7(5): 4-5.

Alkema L, Chou D, Hogan D, Zhang S, Moller AB, Gemmill A, et al (2016). Global, regional, and national levels and trends in maternal mortality between 1990 and 2015, with scenario-based projections to 2030: a systematic analysis by the UN Maternal Mortality Estimation InterAgency Group.Lancet, 387 (10017): 462-474.

Anwar AD, Harsono AB, Sasotya RMS, Amarullah MN, Hidayat D. (2013).Bandung Controversies and Consensus in Obstetrics \& gynecology. Jakarta: CV Sagung Seto.

Cunningham FG, Lenovo KL, Bloom SL, Hauth JC et al. (2005)Obstetri Williams Edisi 21. Jakarta: EGC.

Dinas Kesehatan Aceh. (2017). Profil kesehatan aceh 2016.

Dinas Kesehatan Provinsi Aceh. (2016). Profil Kesehatan Aceh 2015.19-22.

Dinas kesehatan Aceh. (2017)Profil Kesehatan Aceh tabun 2016. 25-28.

Dinas Kesehatan Aceh Utara. (2017).Laporan PWS Aceh Utara 2017.

Gabbe SG, Gabbe JR, Berghella V, Galan HL, Grobman WA, Simpson JL. (2017). Obstetrics: Normal and Problem Pregnancies. Ed 7. Elsevier.

Hanif. (2018).Tapak Tilas Kasus Kematian Ibu dan Bayi di Aceh. Banda Aceh, 3 Februari.

KEMENKES RI. (2018).Laporan Kinerja Ditjen Kesehatan Masyarakat tabun 2017. Direktorat Jenderal Kementrian Kesehatan 2018.

Kristi NL, Suprihatiningsih, Prasetyowati. (2011). Hubungan induksi oksitosin dan paritas dengan kejadian atonia uteri pada ibu bersalin yang mengalami perdarahan post partum di rsud a. Yani metro tahun 2010. J Kesehatan Metro Sai Wawai. 4(1): 9-15.

Lestari GI. (2014). Analisis Hubungan Anemia Dengan Perdarahan Postpartum Di Rsud Jendral Ahmad Yani Kota Metro Tahun 2013. Jurnal Kesehatan Metro Sai Wawai. 7(2):65-75.

Lisonkova A. Mehrabadi A, Allen VM, Bujold E, Crane J, Gaudet L. (2016). Atonic postpartum hemorrhage: blood loss, risk factor, and third stage management. J Obstet Gynaecol Can. 38(12): 1081-1090.

Manuaba, Ida BG. (2008).ilmu kebidanan, penyakit kandungan dan keluarga berencana. Jakarta: Buku kedokteran EGC.

Nurchairina. (2017). Hubungan Overdistensi Uterus Dengan Kejadian Atonia Uteri Pada Ibu Post Partum Di Sebuah Rumah Sakit Di Provinsi Lampung. Jurnal Keperawatan.13(2):21520.

Puskesmas PONED Nisam. (2018).Buku Register tabun 2015-2017.

Puskesmas PONED Lhoksukon. (2018). Buku Register tahun 2015-2017.

Puskesmas PONED Krung Mane (Muara Batu). (2018). Buku Register tahun 2015-2017.

Rumah Sakit Umum Cut Meutia. (2018) Data Rekam Medik tahun 2015-2018.

Say L, Chou D, Gemmill A, Tunçalp O, Moller AB, Daniels JD, et al (2014). Global Causes of Maternal Death: A WHO Systematic Analysis. Lancet Global Health.;2(6): e323-e333.

Tenore JL. (2003) Methods for cervikal ripening and induction of labour. Am Fam Physc. 67(10): 2123-8

Wetta LA, Szychows JM , Seals S, Mancuso MS, Biggio JR, Tita AT. (2013). Risk factors for uterine atony/postpartum hemorrhage requiring treatment after vaginal delivery. Am J Obstet Gynecol.209:51.e16. 
WHO, UNICEF, UNFPA, World Bank, the United Nations Population Division. (2015). Trends in Maternal Mortality: 1990 to 2015. WHO, UNICEF, UNFPA, World Bank Group and the United Nations Population Division.
Wiknjosastro, Hanifa.(2008). Ilmu Kebidanan. Jakarta: Yayasan Bina Pustaka Sarwono Prawirohardjo 